\title{
Bio polyetherurethane composites with high content of natural ingredients: hydroxylated soybean oil based polyol, bio glycol and microcrystalline cellulose
}

\author{
Ewa Głowińska $\cdot$ Janusz Datta
}

Received: 22 July 2015/ Accepted: 16 November 2015/Published online: 21 November 2015

(C) The Author(s) 2015. This article is published with open access at Springerlink.com

\begin{abstract}
In our study, we focused on obtaining biopolyurethane composites using bio-components such as bio glycol, modified natural oil-based polyol, and microcrystalline cellulose (MCC). The pre-polymer method was used to prepare the bio polyurethane matrix. Prepolymer was synthesized using 4,4'diphenylmethane diisocyanate and a polyol mixture containing $50 \mathrm{wt} \%$ of commercial polyether and $50 \mathrm{wt} \%$ of hydroxylated soybean oil (H3). Bio based 1,3-propanediol (1,3bioPDO) was used as the prepolymer chain extender. The composites were produced by dispersing 5, 10, 15 and $20 \mathrm{wt} \%$ of MCC in the bio polyurethane matrix. The polymerization was catalyzed with 1,4-diazabicyclo[2.2.2]octane. The influence of the added MCC powder on the structure and thermal properties of the obtained composites was investigated. The FTIR analysis demonstrated that the MCC admixture affected the absorbance of $\mathrm{C}-\mathrm{O}-\mathrm{C}$ and $\mathrm{C}=\mathrm{O}$ groups and the phase separation index of the obtained bio-polyurethanes composites. The results of mechanical tests and scanning microscopy images indicated good interfacial adhesion between the partially bio-based matrix of the composite and bio-filler. The results of thermomechanical analysis showed that the application of MCC as a filler has a positive effect on the storage and loss modulus of the composites.
\end{abstract}

E. Głowińska $(\bowtie) \cdot$ J. Datta

Gdansk University of Technology, G. Narutowicza Street

11/12, 80-233 Gdańsk, Poland

e-mail: ewaglowi@pg.gda.pl
Keywords Bio based 1,3-propanediol · Bio glycol · Microcrystalline cellulose $\cdot$ Modified soybean oil $\cdot$ Bio composites $\cdot$ Bio polyurethane

\section{Introduction}

Due to a great interest in polymer composites, this class of materials is constantly improved and further developed. Because of their versatile properties, improved safety and economic aspects, polymer composites are more frequently used, particularly in the construction industry, aviation and automotive industry (Datta and Kopczyńska 2015; Naheed et al. 2014; Mówczyński 2012; Bledzki et al. 2006). Composites are employed in complex constructions, and layered and construction materials. At present, composites reinforced with fibers dominate the market because of their improved mechanical and strength properties and minimized weight in comparison to the traditional non-polymeric composites. However, the increased quality of fiber-reinforced composites is associated with the higher cost, which limits the applications of these materials. The mechanism of operation of fiber-reinforced composites is based on the load transfer by different fiber types. The matrix functions as glue holding the fibers together as well as a direct barrier against external factors. Natural fibers used in the production of such composites can be 
either continuous or discontinuous (Rajczyk and Stachecki 2011).

Composites display different properties which depend on the initial components applied in their production. The composites based on natural fibers are used to produce specialized industrial products such as, rolling element bearings of printing devices, housings of computers and other devices, medical equipment, and the elements of wind turbines. The polymer-based composites are considered to be the materials with the highest strength-to-weight ratio which are also characterized by elasticity and stretchability. The global market of polymer composites is dynamically expanding and this trend will continue in the future because of the new applications for these materials. The total market value of polymer-based composites has been estimated at ca. $\$ 60$ billion dollars, with the annual increase exceeding that of global GDP. The main factors influencing the intensive development in the field of composite materials are the expansion of businesses using these materials, technological development, a significant potential for the improvement of produced composites, and better production efficiency (Mówczyński 2012). Moreover, the application of specially grown plants that cannot be used for human consumption also helps in the development of composites as well as the sustainable development of industry and agriculture (Fowler et al. 2006). For many years, the use of wood-derived raw materials such as wood powder and wood fibers, or cellulose and lignin for reinforcing polymeric materials has been a continuously developing trend in materials science research. This is due to the fact that wood-derived fillers are advantageous compared to conventional fibers, i.e. they are a sustainable material commonly present in nature, characterized by low relative density, high strength and rigidity, and relatively low cost (Głowińska et al. 2015; Alamri et al. 2012; Datta and Glowinska 2011; Kiziltas et al. 2011; Magnus et al. 2007; Avérous and Le Digabel 2006). Moreover, from among wood-derived raw materials, lignin can be used in the production of polyurethanes as liquid polyol component instead of commercial polyols (Xue et al. 2014; Li et al. 2012). The methods for obtaining polyester polyols by using lignin originating from hard and soft wood, and recycled paper have been described in the published literature. The process of polyol production is conducted with the use of glycols in the presence of $p$ - toluenesulfonic acid as a catalyst. The obtained material, called liquid wood-based polyol, is employed in the synthesis of rigid polyurethane foams (Kunaver et al. 2011).

Polymer materials filled with particles in the form of powders or fibers display the structural boundary region between the filler and the matrix, which is a few micrometers thick. Adhesion processes take place in this region. Adhesion mainly depends on the wetting of the filler by a liquid polymer and its adsorption. The forces of adhesion increase with increasing wettability and adsorption. As a result, the obtained composite shows better mechanical resistance. However, it is not always the case that the addition of filler improves the strength of the modified materials. In order to increase adhesion between the filler and the matrix, modifications aimed at improving the fiber wettability with the polymer are applied. Theoretically, the addition of spherical or approximately spherical filler should not result in anisotropy in the obtained composite (Koleśnik-Nykiel 2013).

Microcrystalline cellulose (MCC) is a sustainable powdered filler whose properties are determined by adhesion between the hydrophobic matrix and hydrophilic filler. MCC is a pure and partially depolymerized form of native cellulose, which occurs as white crystalline powder without odor and taste, characterized by porous particles. Cellulose is a carbohydrate consisting of 1,4- $\beta$-D-glucose monomers (Chen et al. 2014; Azubuike and Okhamafe 2012; Hatakeyama et al.2012; Oyeniyi and Itiola 2012; Kiziltas et al. 2011; Ejikeme 2008).

The hydrophilic properties of cellulose are used in inter alia, polyurethane foam-based composites (Luo et al. 2013; Hatakeyama et al. 2012). Cellulose can be employed in the production of shape memory materials with the polyurethane matrix (Siró and Plackett 2010), plasticized starch-based composites (Cao et al. 2008), and PET-PTT blends (Kiziltas et al. 2011).

In our earlier publication, we presented the results of mechanical, thermomechanical and microstructural analysis of the composites based on the bio-PU matrix synthesized with the use of $25 \mathrm{wt} \%$ of hydroxylated soybean oil, bio glycol and microcrystalline cellulose as a filler (Głowińska and Datta 2015). The aim of this study was to investigate the influence of MCC filler dispersed in the bio-polyurethane matrix containing $50 \%$ of bio based polyol on the degree of phase separation and thermomechanical 
properties of the obtained composites. The aforementioned parameters were determined by means of spectroscopy, and thermal and mechanical testing under static and dynamic conditions. The chemical resistance of the composites to selected media was also assessed.

\section{Experimental}

The bio-based polyurethanes (PU) obtained via the prepolymer method were filled with the microcrystalline cellulose (MCC) powder (International Fiber Corporation, Belgium). The filler was degreased prior to use. Prepolymer was synthesized from diisocyanate MDI (BorsodChem, Hungary) and a polyol mixture consisting of $50 \mathrm{wt} \%$ of commercial polyether PTMG, Mn 2000 (Overlack, Poland) and $50 \mathrm{wt} \%$ of hydroxylated soybean oil $\mathrm{H} 3, \mathrm{Mn} \sim 735$ and functionality $\sim 2.6$, previously modified with a lowmolecular-weight bioglycol (bio-1,3-propanediol). The reaction was conducted at $80{ }^{\circ} \mathrm{C}$ for $1 \mathrm{~h}$. During the second stage of the process, the prepolymer chains were extended by using bio-1,3-propanediol (DuPont, USA) with $0.3 \mathrm{wt} \%$ of 1,4-diazabicyclo[2.2.2] octane (DABCO, Merck, Germany) as a catalyst. The molar ratio $[\mathrm{NCO}]_{\text {prepolymer }} /[\mathrm{OH}]_{\text {chain extender }}$ equaled 1.05:1. The bio polyurethane systems were filled with 5,10 , 15 and $20 \mathrm{wt} \%$ of MCC and later molded using a hydraulic press. The content of hard segments in bio polyurethane matrix was calculated as about $39 \%$. The scheme of bio-polyurethane synthesis via prepolymer method was described in our previous papers (Datta and Głowińska 2014; Głowińska and Datta 2014).

\section{Measurement}

\section{FT-IR spectroscopy}

Spectroscopic analysis of bio-polyurethanes was carried out using a FTIR Nicolet 8700 spectrophotometer (Thermo Electron Corporation) and ATR technique; a Specac Heated Golden Gate single reflection diamond ATR accessory was used. Spectra were registered at room temperature for the wavenumbers ranging from
500 to $4500 \mathrm{~cm}^{-1}$ at $4 \mathrm{~cm}^{-1}$ nominal resolution. Each spectrum was an average of 128 independent scans.

Based on FTIR analysis, the degrees of phase separation (DPS) were calculated using the following equations (Tien and Wei 2001):

$D P S=\frac{R}{R+1}$

$D P M=1-D P S$

$R=\frac{A_{b}}{A_{f}}$

where $\mathrm{R}$ - carbonyl hydrogen bonding index; $\mathrm{A}_{b}-$ absorption intensity of hydrogen-bonded carbonyl; $\mathrm{A}_{\mathrm{f}}$-absorption intensity of free carbonyl.

DMA

Dynamic mechanical analysis of bio polyurethanes was performed using a DMA Q800 Analyzer (TA Instruments) under nitrogen atmosphere. The measurements were made at a temperature range from -100 to $+150{ }^{\circ} \mathrm{C}$, at an operating frequency of $10 \mathrm{~Hz}$, with a heating rate of $4{ }^{\circ} \mathrm{C} / \mathrm{min}$. The values of storage modulus, loss modulus and glass transition temperature were also calculated.

TGA

Thermogravimetric analysis (TGA) was carried out using a NETZSCH TG 209F3 analyzer under nitrogen atmosphere at a heating rate of $20 \mathrm{~K} / \mathrm{min}$ and temperature range from 35 to $600{ }^{\circ} \mathrm{C}$. The results of the TGA analysis were presented on the TG and DTG curves. The graphs have been started from $150{ }^{\circ} \mathrm{C}$. Below this temperature occurs only the water loss.

\section{SEM analysis}

The microscopic analysis was conducted on the cross section of samples using a Quanta FEG scanning electron microscope under the following conditions: magnification between 500 and 10,000, the EverhartThornley detector (ETD), and a high vacuum at 10.00 or $20.00 \mathrm{kV}$ at a working distance of $10 \mathrm{~mm}$. Samples were coated with gold prior to microscopic observation. 
Tensile test

The tensile strength $\left(\mathrm{TS}_{\mathrm{b}}\right)$ and elongation at break $\left(\mathrm{E}_{\mathrm{b}}\right)$ were measured under static pressure by using a Zwick Z020 tensile-testing machine, in accordance with the EN ISO 527-1:1996 and EN ISO 527-2:1996 standards. The dumbbell-shaped samples of standard dimensions were also tested at a rate of $50 \mathrm{~mm}$ per minute. The measurements were performed at room temperature.

\section{Hardness}

Hardness was measured according to the PN-EN ISO 868:2005 standard. The circular samples $(56 \times$ $6 \mathrm{~mm}$ ) were placed on a flat surface, and ten measurements were taken per sample by applying a Shore A durometer for $3 \mathrm{~s}$.

\section{Rebound resilience}

Rebound resilience was determined by means of a Rebound Tester in accordance with the ISO 4662:2009 standard. Rebound resilience is measured by dropping a free-falling pendulum hammer from a given height, which impacts the sample. The amount of energy is shown on a pendulum scale. Ten measurements were recorded per sample.

\section{Abrasion resistance}

Abrasion resistance was tested with an Abrasion Check instrument (Gibitre instruments) in accordance with the ISO 4649:2010 standard. The value of abrasion resistance was calculated according to the following formula:

$V=\frac{\left(m_{1}-m_{2}\right) \cdot 0.2}{\rho \cdot \Delta m_{w}}\left(\mathrm{~cm}^{3}\right)$

where $\mathrm{m}_{1}$ - the weight of the sample before the test $(\mathrm{g}) ; \mathrm{m}_{2}$ - the weight of the sample after the test $(\mathrm{g})$; 0.2 - the required mass loss of the standard sample $(\mathrm{g})$; $\rho$ - the density of the analyzed material $\left(\mathrm{g} / \mathrm{cm}^{3}\right)$; and $\Delta \mathrm{m}_{\mathrm{w}}$ - the arithmetic mean of the mass loss of three standard samples (g).
Density

Density was determined according to the PN-EN ISO 1183-1:2013-06 standard. The measurements were performed in methanol at $23 \pm 2{ }^{\circ} \mathrm{C}$.

Chemical resistance

The chemical resistance of composites was determined based on swelling test in accordance with the PN-ISO 1817-2001 standard. The measurements were performed in two liquids with different polarities, i.e. acetone and toluene. Each sample weighting $0.3 \mathrm{~g}$ (balance precision $0.0001 \mathrm{~g}$ ) was placed in a separate tightly-closed container filled with a fluid. The measurements were recorded after 1, 24, 48, 72, 96, 120 and $168 \mathrm{~h}$ of sample exposure to the liquid.

The value of degree of swelling was calculated from the following formula:

$P=\frac{m_{1}-m_{0}}{m_{0}} \times 100 \%$

where $\mathrm{m}_{0}$ - the mass of dry sample mass before the measurement of thickness swelling $(\mathrm{g}) ; \mathrm{m}_{1}$ - the mass of sample after the swelling (g).

\section{Results and discussion}

FT-IR spectroscopy analysis

The FTIR-ATR spectra of bio-polyurethane-based composites containing different amounts of MCC are presented in Fig. 1. These spectra were compared to the spectrum of bio polyurethane in order to determine how the presence of filler affects the matrix structure. The wavenumber value of $3327 \mathrm{~cm}^{-1}$ corresponds to the stretching vibration of $\mathrm{NH}$ bond. The band at $1537 \mathrm{~cm}^{-1}$ is attributable to the bending vibration of $\mathrm{NH}$ bond which is characteristic of the urethane group. The wavenumbers of 2854 and $2918 \mathrm{~cm}^{-1}$ correspond to the stretching vibrations of $\mathrm{CH}_{2}$ group, while the wavenumber value of $1412 \mathrm{~cm}^{-1}$, to the deformation vibrations of the same group. The valent vibration of carbonyl group presented in the structure of synthesized polyurethanes and derived from the esther groups of the polyol, both for free and hydrogen 
Fig. 1 FTIR-ATR spectra of bio-polyurethane composites containing 5,10 , 15 and $20 \mathrm{wt} \%$ of MCC

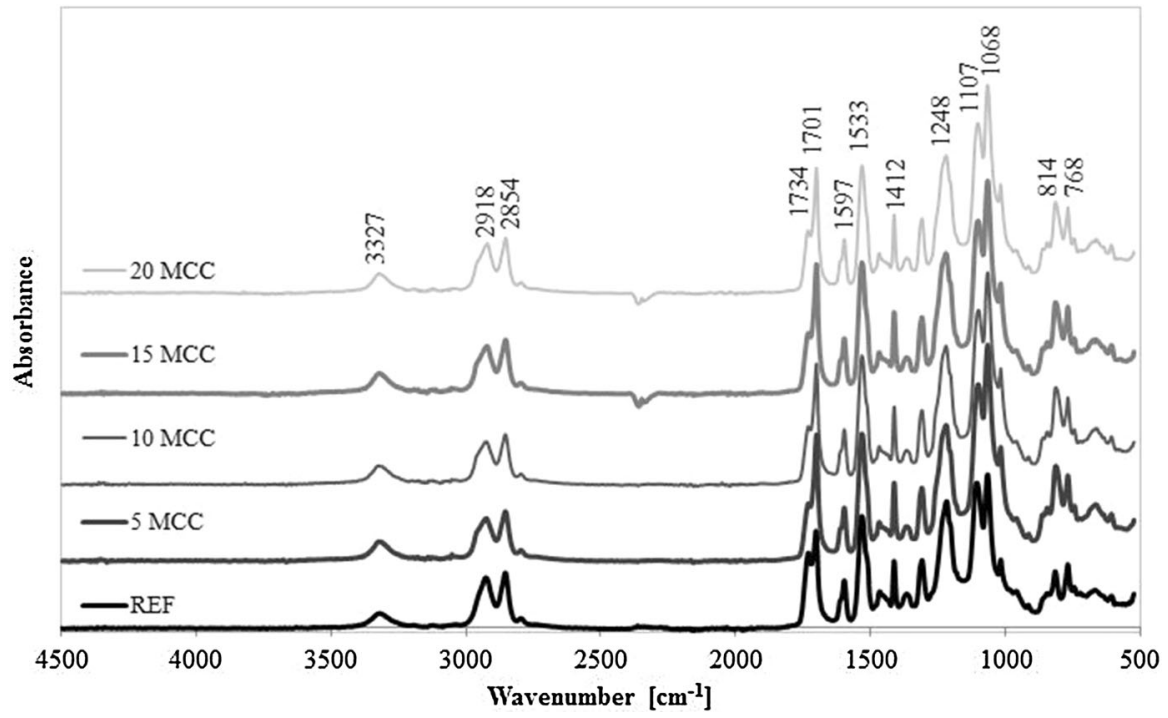

Fig. 2 The FTIR-ATR spectra of bio-polyurethane composites containing 5,10 , 15 and $20 \mathrm{wt} \%$ of MCC for the wavenumber range from 900 to $1900 \mathrm{~cm}^{-1}$

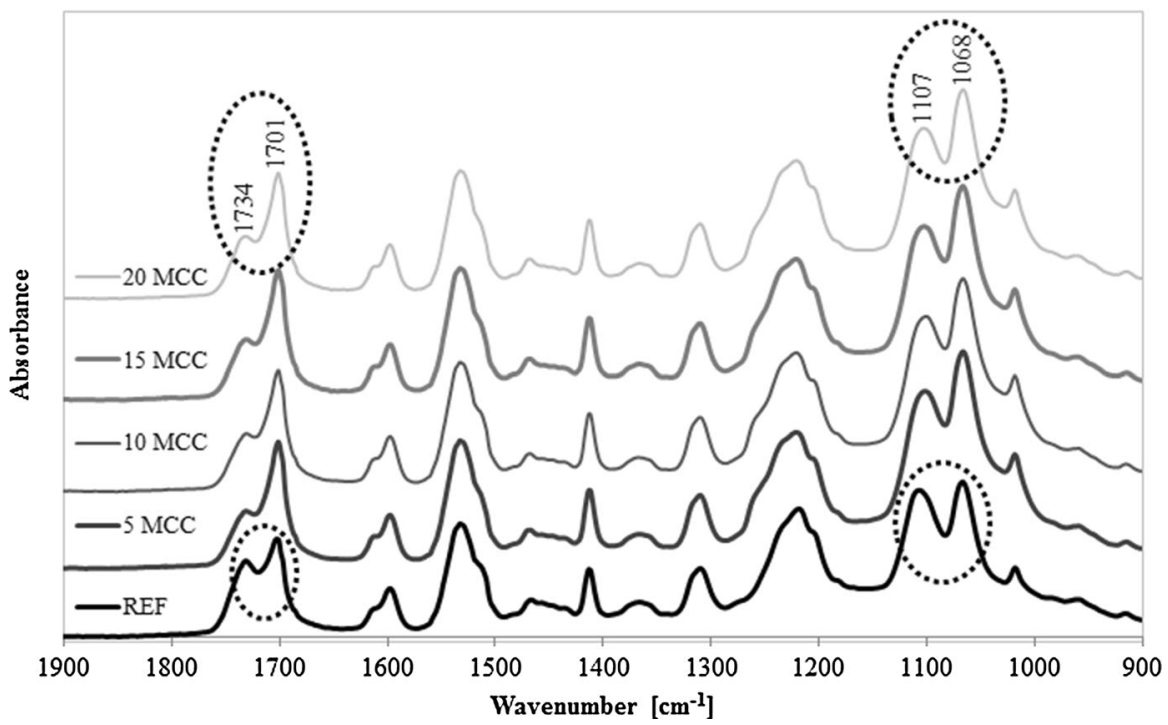

bonded carbonyl groups manifests itself as a multiplet at a wavenumber range from 1701 to $1734 \mathrm{~cm}^{-1}$, while the stretching vibration of $\mathrm{C}=\mathrm{O}$ group occurs at $1220 \mathrm{~cm}^{-1}$.

The differences in band intensity (Fig. 2) at 1110 and $1065 \mathrm{~cm}^{-1}$ were observed which are attributable to asymmetric stretching vibrations of $\mathrm{C}-\mathrm{O}-\mathrm{C}$ group. For the wavenumbers 1110 and $1065 \mathrm{~cm}^{-1}$, the vibrations corresponding to free $\mathrm{C}-\mathrm{O}-\mathrm{C}$ group and hydrogenbonded C-O-C group were present, respectively (Datta and Głowińska 2014; Prociak et al. 2014). The differences in band intensity in this range were not observed in the case of composite materials containing lower amount of polyol H3 group (Głowińska and Datta 2015). Changes in the intensity of these bands and within the vibrations characteristic of $\mathrm{C}=\mathrm{O}$ group indicate that there are hydrogen bonds between the matrix and the filler containing the $1^{\circ}$ and $2^{\circ}$ hydroxyl groups.

Based on Eqs. (1) and (3), the degree of phase separation was calculated in dependence on the amount of MCC dispersed in the bio-polyurethane 


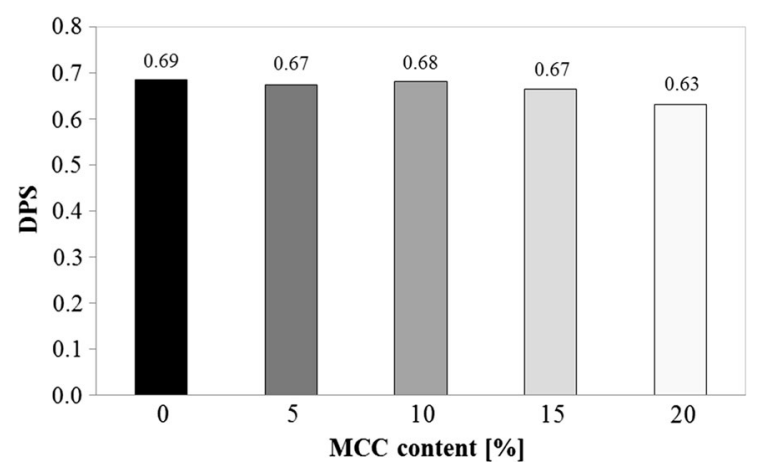

Fig. 3 Changes in the degree of phase separation (DPS) for biopolyurethane composites containing different amounts of MCC

matrix (Fig. 3). The obtained DPS values suggested the occurrence of chemical interactions between the filler and the matrix, especially in the case of composites containing the highest MCC content, resulted in lower value of phase separation. These interactions can be caused by presence of hydroxyl groups in MCC and free isocyanate groups in the matrix at the stage of the PU system formation. The formation of hydrogen bonds between the carbonyl groups and $\mathrm{NH}$ in the urethane groups leads to the creation of rigid domains, and favors the process of microphase separation. When the hydrogen bonds start to form between the $\mathrm{NH}$ groups and the $\mathrm{C}(\mathrm{O}) \mathrm{O}$ or $\mathrm{C}-\mathrm{O}-\mathrm{C}$ groups, the latter being a structural element of elastic segments, the phase dispersion occurs (Prociak et al. 2014).

Dynamic mechanical analysis

The results of dynamic thermomechanical analysis of the composites containing from 5 to $20 \mathrm{wt} \%$ of microcrystalline cellulose (MCC) are shown in Figs. 4 and 5 and in Table 1. Based on the analyzed data, it can be stated that the application of MCC as a reinforcement of the bio polyurethane matrix had a positive effect, including other previously described materials with a lower content of $\mathrm{H} 3$ bio based polyol (Głowińska and Datta 2015). Irrespective of the MCC content, the storage modulus of the composites (Fig. 4) were higher than that of the matrix in whole range of temperature. The maximum $\mathrm{E}^{\prime}$ value was observed for the composite containing $15 \mathrm{wt} \%$ of $\mathrm{MCC}$ in the temperature range from -100 to $-34{ }^{\circ} \mathrm{C}$. Over this temperature it can be observed that the

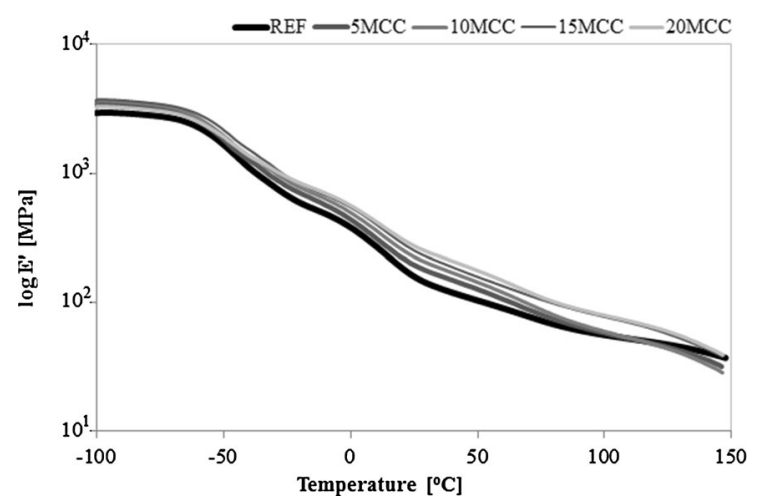

Fig. 4 The $\log E^{\prime}$ as a function of temperature for biopolyurethane composites filled with MCC

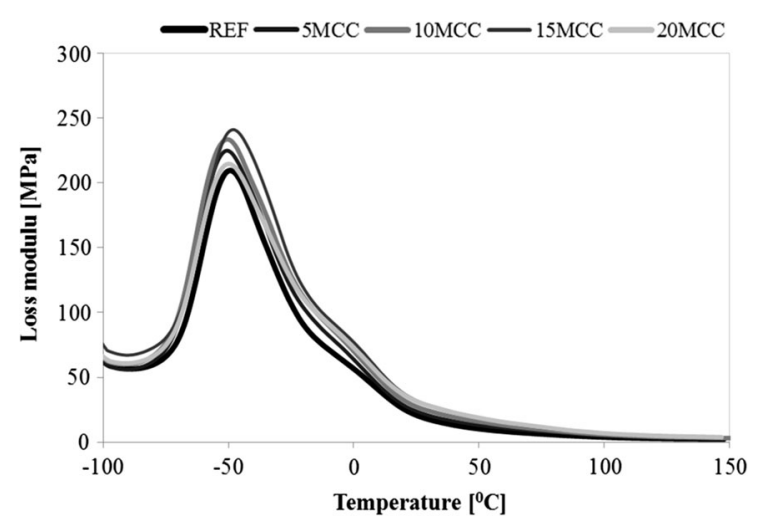

Fig. 5 The loss modulus as a function of temperature for biopolyurethane composites filled with MCC

heights value of $\mathrm{E}^{\prime}$ was noted for composites containing $20 \mathrm{wt} \%$ of filler. Generally, the composite samples were characterized by elevated rigidity due to the incorporation of hard microcrystalline cellulose fibers into the elastomeric matrix.

The loss modulus $\left(\mathrm{E}^{\prime \prime}\right)$ also strongly depended on the amount of admixed MCC. The $\mathrm{E}^{\prime \prime}$ values decreased with increasing amount of filler in the matrix (Fig. 5). The composite materials are characterized by the loss modulus in the range from 210 to $240 \mathrm{MPa}$; these values are higher compared to the reference material, namely, the matrix (REF). The elevated values of loss modulus of the obtained composites are disadvantageous because more energy is irreversibly lost by the materials due to the dispersion of rigid and short MCC fibers in the matrix. 
Table 1 The values of glass transition temperature and loss tangent for bio-polyurethane-based composites containing MCC

\begin{tabular}{llllll}
\hline Properties & \multicolumn{5}{l}{ MCC content (wt\%) } \\
\cline { 2 - 6 } & REF-0 & 5 & 10 & 15 & 20 \\
\hline $\operatorname{Tan}_{1}(-)$ & 0.16 & 0.15 & 0.15 & 0.15 & 0.14 \\
$\operatorname{Tan}_{2}(-)$ & 0.15 & 0.14 & 0.14 & 0.14 & 0.13 \\
$\operatorname{Tg}_{1}\left({ }^{\circ} \mathrm{C}\right)$ & -34 & -32 & -31 & -31 & -33 \\
$\operatorname{Tg}_{1}\left({ }^{\circ} \mathrm{C}\right)$ & 7 & 2 & 3 & 3 & 2 \\
\hline
\end{tabular}

The values of glass transition temperature for different composite samples ranged from -31 to $-34{ }^{\circ} \mathrm{C}$ (Table 1). For all samples, the glass transition temperature during the first transition $\left(\mathrm{Tg}_{1}\right)$ equaled ca. $-35{ }^{\circ} \mathrm{C}$, which corresponds to the phase transition of elastomeric materials. The second glass transition $\left(\mathrm{Tg}_{2}\right)$ at around $0{ }^{\circ} \mathrm{C}$ is most likely related to the presence of modified soybean oil. The values of $\tan \delta$ $\left(\tan \delta_{1}\right.$ and $\left.\tan \delta_{2}\right)$ of the reference material were larger compared to the composites. However, the addition of MCC to the bio-polyurethane matrix caused only a small decrease in the value of loss modulus, which means that the dissipation properties of the materials decreased slightly. The coefficient values are characteristic of the material with good dissipation properties (Datta and Głowińska 2014).

\section{Thermogravimetry analysis (TGA)}

The samples of composites containing $15 \mathrm{wt} \%$ of $\mathrm{MCC}$, reference material (matrix) and microcrystalline cellulose (MCC) were analyzed by thermogravimetry. Based on the obtained data, the effect of MCC admixture on the thermal decomposition of the composite materials was determined (Figs. 6, 7).

The thermal decomposition of the bio-polyurethane composites containing MCC took place in three steps, while the thermal decomposition of reference material was a two-step process. In the first step, both the biopolyurethane matrix and the composite decomposed via breaking of urethane bonds in hard segments (isocyanate component and a low-molecular-weight extender). The second step of matrix decomposition and the third step of composite decomposition, the latter occurring at elevated temperatures, is associated with the elastic segments, i.e. a polyol component. The thermal degradation of the filler took place at a

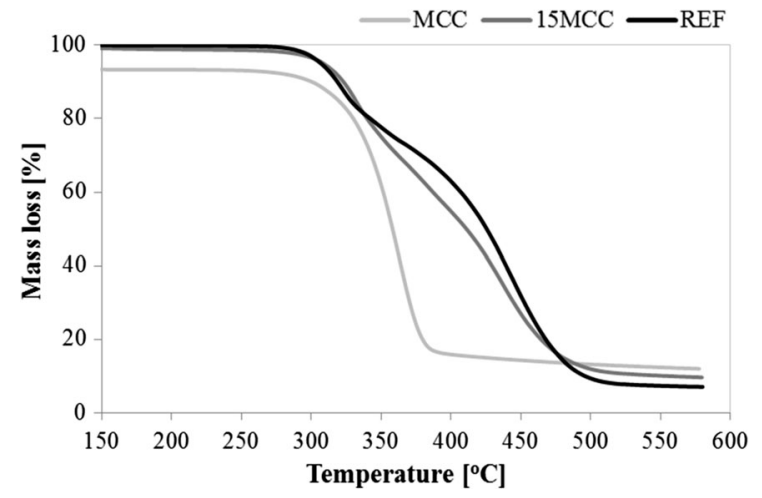

Fig. 6 Mass loss versus temperature plotted for the composite materials, reference sample, and MCC

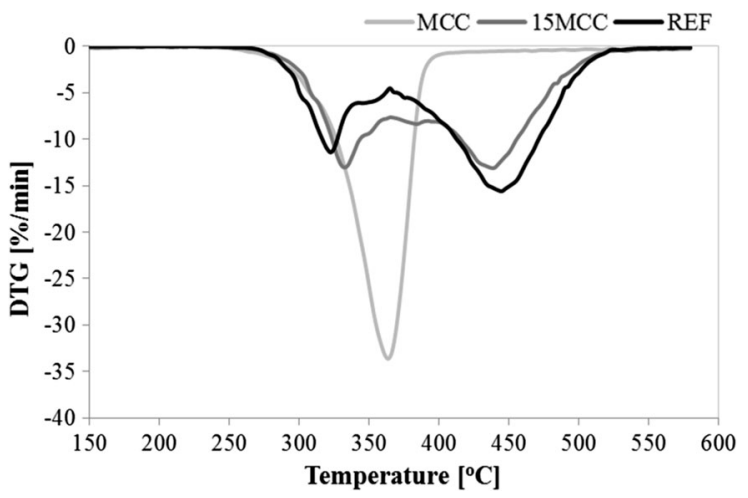

Fig. 7 The first derivative of the mass loss versus temperature curve for the composite materials, reference sample, and MCC

temperature lower than that of the onset of elastic segment decomposition. The admixture of MCC resulted in a slight increase of the thermal decomposition rate compared to that of the matrix (Figs. 6, 7).

The thermal decomposition temperatures of biopolyurethane-based composites are listed in Table 2. Based on the obtained data, it was concluded that the addition of natural filler in the form of MCC did not lower the thermal degradation temperatures corresponding to 5, 10, 50 and $90 \%$ weight loss $\left(\mathrm{T}_{5 \%}, \mathrm{~T}_{10 \%}\right.$,

Table 2 Thermal degradation temperatures of the bio-polyurethane composites containing MCC

\begin{tabular}{lllll}
\hline Code of sample & \multicolumn{4}{l}{ Temperature $\left({ }^{\circ} \mathrm{C}\right)$} \\
\cline { 2 - 5 } & $\mathrm{T}_{5 \%}$ & $\mathrm{~T}_{10 \%}$ & $\mathrm{~T}_{50 \%}$ & $\mathrm{~T}_{90 \%}$ \\
\hline REF & 308 & 318 & 425 & 498 \\
$15 \mathrm{MCC}$ & 307 & 322 & 410 & 557 \\
\hline
\end{tabular}


$\mathrm{T}_{50 \%} \mathrm{i}_{90 \%}$, respectively). Moreover, it was found that the value of $\mathrm{T}_{90 \%}$ for the bio-polyurethane composites in the final step of thermal degradation is significantly higher in comparison to the reference materials (Table 2).

\section{Scanning electron microscopy}

The scanning electron microscopy (SEM) images of the composites containing 5 and $20 \mathrm{wt} \%$ of MCC show the uniform distribution of MCC particles. The composites with a higher content of filler in the form of microcrystalline cellulose are characterized by a larger active surface area. Thus, such materials display better adhesion to other surfaces. Based on the image analysis, it can be concluded that the composites have ordered and regular structure. The MCC particles and the matrix form a compact material, with good strength properties (Fig. 8). The SEM images demonstrate that the structure of the composites is more ordered and regular than that of the composites based on the matrix with a lower content of H3 (Głowińska and Datta 2015).

Mechanical properties: tensile test, hardness and elasticity

The results of tensile testing [tensile strength $\left(\mathrm{TS}_{\mathrm{b}}\right)$, elongation at break $\left(\mathrm{E}_{\mathrm{b}}\right)$, Young modulus], hardness and elasticity of bio-polyurethane composites are presented in Table 3.

It was found that the bio-polyurethane composites containing from 5 to $15 \mathrm{wt} \%$ of microcrystalline cellulose displayed the $\mathrm{TS}_{\mathrm{b}}$ values that were slightly higher or close to that of the reference material. This indicates the positive effect of increased filler level on the bio-composite properties, and sufficient adhesion between the MCC particles and the matrix (Fig. 9). Generally, an increase in tensile strength also resulted from phase separation (Nanclares et al. 2015) between the soft and hard segments of the matrix which is favored by the presence of MCC. It was observed that for the higher MCC contents the differences between the $\mathrm{TS}_{\mathrm{b}}$ values were insignificant, i.e. ca. 0.6 MPa. Young modulus of bio-polyurethane composites depended on the amount of MCC. It was observed that with increasing of MCC content the value of Young modulus is higher (Table 3) what is caused by increase of composites stiffness, what is confirmed also by DMA analysis. The increased filler content resulted in increased rigidity of the composites, which was reflected in the values of elongation at break. For the MCC content of only $5 \mathrm{wt} \%$, the value of $\mathrm{E}_{\mathrm{b}}$ decreased by $50 \%$ relative to the reference material (Fig. 9). The increasing amount of MCC, dispersed in the bio-polyurethane matrix, caused a significant decrease in the elongation at break compared to that of the matrix. This can be explained by the higher frequency of contact between MCC and the stretching material, which results in the physical and chemical damage to the composite matrix.

A comparison of the obtained composites and previously described similar materials containing two times less of $\mathrm{H} 3$ polyol was conducted. It was observed that the increased content of soybean oilbased polyol had a positive effect on the composites
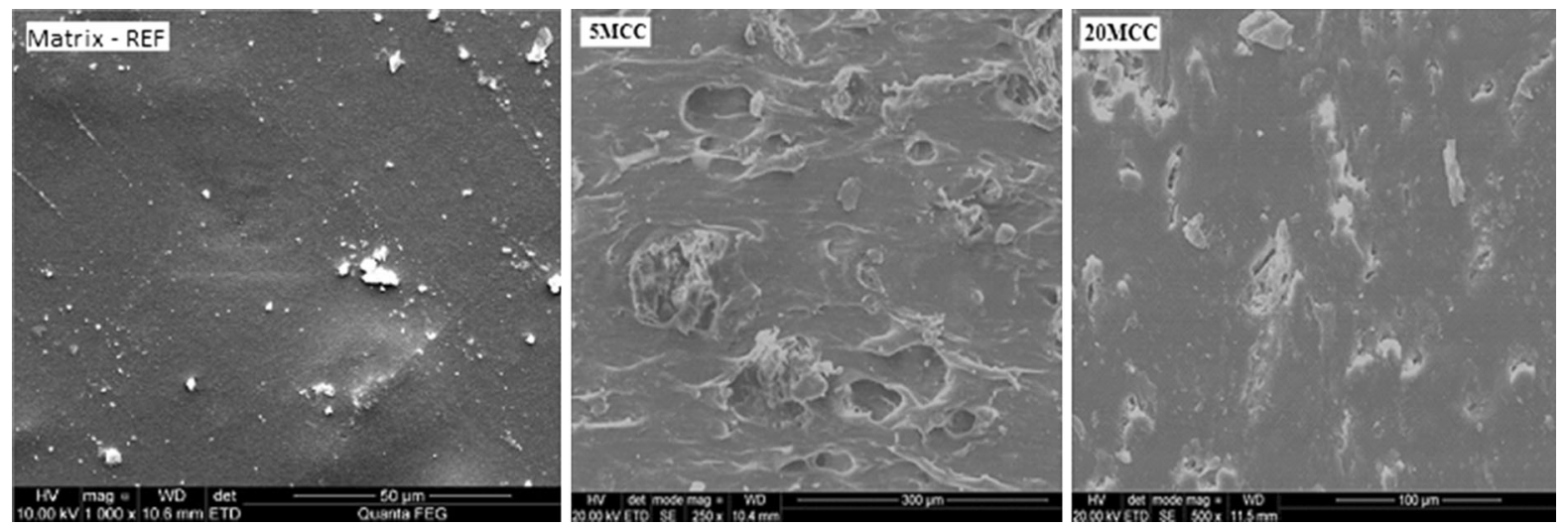

Fig. 8 SEM images of bio-polyurethane composites containing 5 and 20 wt $\%$ of MCC 
Table 3 Mechanical properties of biopolyurethane-based composites containing MCC

\begin{tabular}{lccccc}
\hline Properties & \multicolumn{4}{l}{ MCC content (wt\%) } & \\
\cline { 2 - 6 } & REF-0 & 5 & 10 & 15 & 20 \\
\hline $\mathrm{TS}_{\mathrm{B}}(\mathrm{MPa})$ & $8.1 \pm 0.9$ & $9.2 \pm 0.4$ & $8.2 \pm 0.8$ & $7.7 \pm 0.4$ & $7.5 \pm 1.1$ \\
$\mathrm{E}_{\mathrm{b}}(\%)$ & $102 \pm 22$ & $50 \pm 2$ & $34 \pm 6$ & $17 \pm 1$ & $16 \pm 4$ \\
Young modulus (MPa) & $63.9 \pm 25.8$ & $70.7 \pm 9.8$ & $102.6 \pm 7.4$ & $136.3 \pm 1.9$ & $186.7 \pm 0.7$ \\
Hardness ( $\left.{ }^{\circ} \mathrm{ShA}\right)$ & $92.7 \pm 0.8$ & $92.5 \pm 0.6$ & $93.6 \pm 0.6$ & $93.8 \pm 0.4$ & $92.4 \pm 0.6$ \\
Elasticity (\%) & $39.8 \pm 0.8$ & $37.0 \pm 0.6$ & $36.0 \pm 0.8$ & $34.5 \pm 1.2$ & $31.2 \pm 1.1$ \\
\hline
\end{tabular}

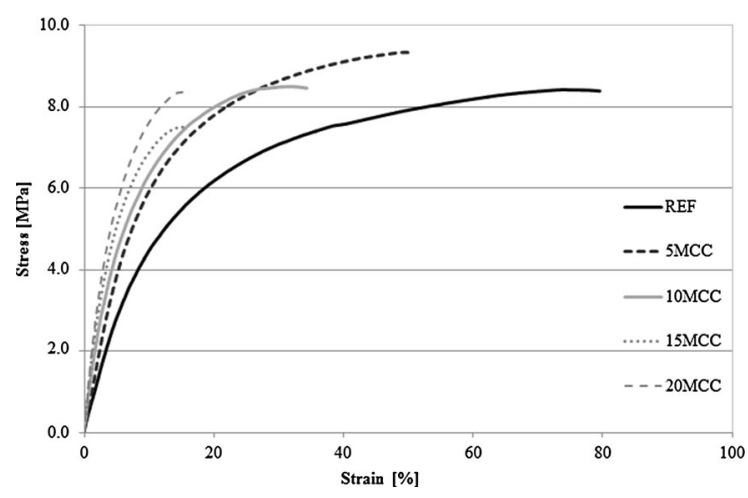

Fig. 9 Tensile strength as a function of elongation plotted for bio-composites filled with different amount of microcrystalline cellulose

modified with MCC. The values of elongation at break significantly decreased in the case of composites containing the same amount of MCC and higher level of polyol H3, which is related to the application of higher amount of polyol with lower molecular weight at the stage of matrix prepolimerization (Głowińska and Datta 2015).

The hardness values of the obtained bio-polyurethane composites containing MCC are presented in Table 3. The hardness of these materials changed in dependence on the filler content; their hardness increased on average by $1.3{ }^{\circ} \mathrm{ShA}$ with increasing MCC content. A similar relationship was observed for the composites based on the matrix containing lower amounts of polyol H3 (Głowińska and Datta 2015). It was found that increase of MCC amount in bio polyurethane matrix does not have significant impact on hardness, what's suggest that between MCC and matrix not occur strong interactions.

Elevated content of MCC in the bio-polyurethane matrix affected the composite elasticity, with the values ranging from 31 to $37 \%$. The elasticity of the composites was lower (up to $9 \%$ ) compared to the reference material (ca. $40 \%$ ). It was found that elasticity decreased with increasing content of microcrystalline cellulose, which resulted from increased rigidity (higher value of loss modulus) and increased hardness of the obtained composites (Table 3 ).

\section{Abrasion resistance}

In Fig. 10 the effect of filler on the abrasion resistance of the obtained composites is illustrated. It was found that the abrasion resistance of the composites increased with increasing MCC level in the biopolyurethane matrix. However, contrary to the composites containing lower amounts of polyol H3 (Głowińska and Datta 2015), a significant decrease in abrasion resistance with increasing MCC content in the matrix was not observed, what is positive.

\section{Density}

The composite samples were characterized by higher density than that of the reference material $(1.112 \mathrm{~g} /$ $\mathrm{cm}^{3}$ ). The density increased with increasing filler

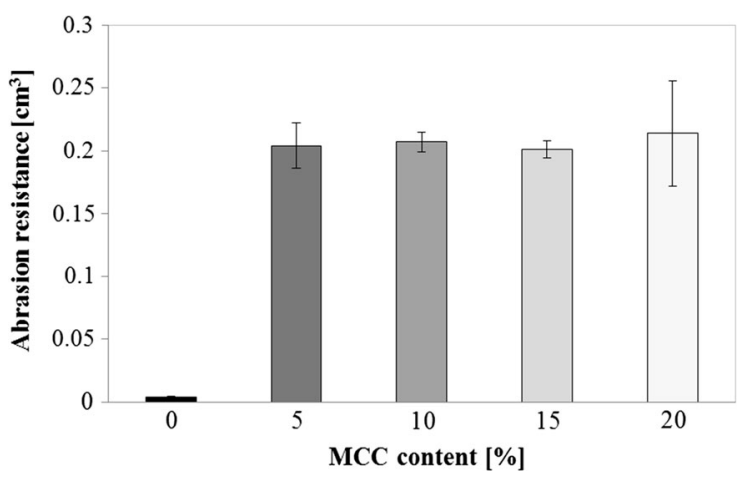

Fig. 10 The effect of microcrystalline cellulose content on the abrasion resistance of filled bio-polyurethane composites 
content, which had been expected due to the fact that the density of the filler is higher that of the matrix. The filling of bio-polyurethane matrix with $5 \mathrm{wt} \%$ of MCC resulted in the average density increase by $0.01 \mathrm{~g} / \mathrm{cm}^{3}$ from $1.125 \mathrm{~g} / \mathrm{cm}^{3}$ for composite containing $5 \mathrm{wt} \%$ of MCC to $1.156 \mathrm{~g} / \mathrm{cm}^{3}$ for material filled with $20 \mathrm{wt} \%$ of microcrystalline cellulose. All composites displayed density values slightly above $1000 \mathrm{~g} / \mathrm{cm}^{3}$.

\section{Chemical resistance}

The chemical resistance of the obtained materials, i.e. matrix and bio-polyurethane composites was determined by swelling test according to the aforementioned Eq. 4. The testing was conducted with two solvents, namely polar acetone and non-polar toluene. The test results are presented graphically in Figs. 11 and 12 .

The chemical analysis demonstrated that both the composites containing dispersed MCC and the reference material do not undergo degradation in the two selected solvents, however, both material types swell when exposed to those solvents. In the case of MCCmodified composites, the degree of swelling in acetone and toluene was similar. The highest degree of swelling was determined for the composite containing $5 \mathrm{wt} \%$ of MCC (Fig. 11). An increase in the MCC level resulted in a slight decrease in degree of swelling, which is related to strong interaction between MCC and bio-polyurethane matrix. An increase in cellulose content by $5 \mathrm{wt} \%$ caused a decrease in the degree of swelling in acetone by ca. $2 \%$, on average. The degree of swelling decreased

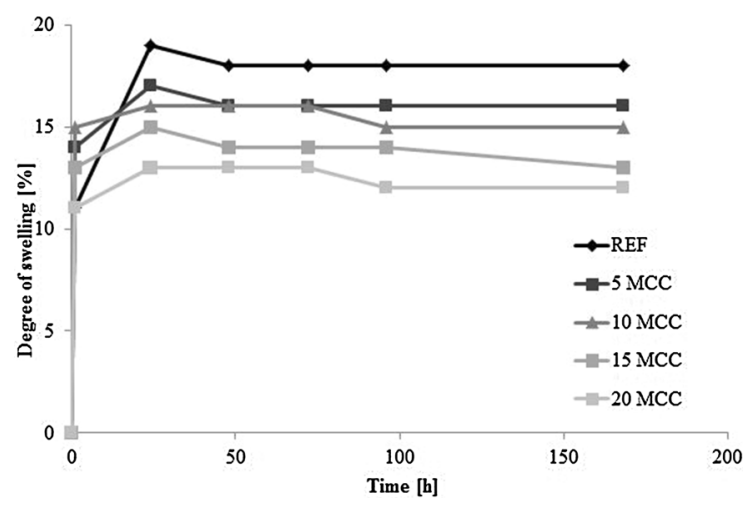

Fig. 11 The effect of MCC content on the swelling of filled bio-polyurethane composites in acetone

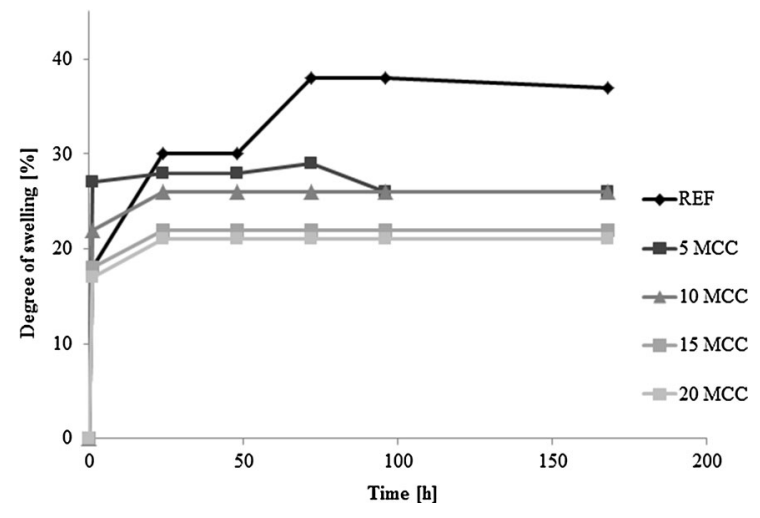

Fig. 12 The effect of MCC content on the swelling of filled bio-polyurethane composites in toluene

with increasing level of MCC in the composite, regardless of solvent type.

The composite samples placed in toluene (polar solvent) displayed higher sorption than those immersed in acetone, while the degree of swelling of reference material was higher than those of the composites. After $24 \mathrm{~h}$ of exposure to the solvent, a visible increase in the sample mass was noticed. The sample mass became stable after $48 \mathrm{~h}$ of exposure in the case of composites filled with 10, 15 and $20 \mathrm{wt} \%$. The leaching of MCC filler to the solvent was not observed.

\section{Summary}

Bio-polyurethane-based composites have significant potential uses therefore the material we developed, due to its structure properties, could be used in a wide range of practical applications, e.g. in automotive and furniture industries. The structure of the obtained composites was analyzed by FTIR. It has been shown that the content of MCC filler affects the phase separation of the composite matrix. This indicates that there is sufficient good adhesion between the filler and the matrix. Dynamic mechanical thermal analysis demonstrated that increased MCC content in the biopolyurethane matrix has a positive effect on the storage and loss modulus, and it also slightly changes the values of glass transition temperature of the obtained composites. The morphological analysis of composites containing microcrystalline cellulose via SEM showed that the composite structure is uniform. The obtained bio-polyurethane composites filled with 
MCC were characterized by good strength. With increasing $\mathrm{wt} \%$ content of $\mathrm{MCC}$ in the matrix the value of $\mathrm{TS}_{\mathrm{B}}$ slightly increased, while the value of $\mathrm{E}_{\mathrm{b}}$ decreased. Moreover, it was observed that increased MCC content influenced small changes in the hardness, elasticity. Abrasion resistance of composites is lower in comparison to bio polyurethane matrix The composite materials filled with MCC were subjected to chemical tests in order to determine their resistance to polar and non-polar solvents. It was demonstrated that the degree of swelling decreased with increasing level of filler in the composite. In comparison to previously described composite materials (Głowińska and Datta 2015), we observed that the selected mechanical properties of composites containing a twofold higher amount of soybean polyol improved. Also, the obtained bio-polyurethane composites containing dispersed MCC were more comprehensively characterized because of the additional parameters such as, calculated degree of phase separation, thermal properties, and chemical resistance to polar and nonpolar media.

Acknowledgments The authors wish to thank DuPont Company (USA) and International Fiber Corporation (Belgium) for kindly providing the bio glycol and microcrystalline cellulose.

Open Access This article is distributed under the terms of the Creative Commons Attribution 4.0 International License (http:// creativecommons.org/licenses/by/4.0/), which permits unrestricted use, distribution, and reproduction in any medium, provided you give appropriate credit to the original author(s) and the source, provide a link to the Creative Commons license, and indicate if changes were made.

\section{References}

Alamri H, Low I, Alothman Z (2012) Mechanical, thermal and microstructural characteristics of cellulose fibre reinforced epoxy/organoclay nanocomposites. Compos Part B 43: 2762-2771

Avérous L, Le Digabel F (2006) Properties of biocomposites based on lignocellulosic fillers. Carbhyd Polym 66:480-493

Azubuike CP, Okhamafe AO (2012) Physicochemical, spectroscopic and thermal properties of microcrystalline cellulose derived from corn cobs. Int J Recycl Org Waste Agric 1:9. doi:10.1186/2251-7715-1-9

Bledzki AK, Faruk O, Sperber VE (2006) Cars from bio-fibres. Macromol Mater Eng 291:449-457
Cao X, Chen Y, Chang PR, Muir AD, Falk G (2008) Starchbased nanocomposites reinforced with flax cellulose nanocrystals. Express Polym Lett 2(7):502-510

Chen WJ, Gu J, Xu SH (2014) Exploring nanocrystalline cellulose as a green alternative of carbon black in natural rubber/butadiene rubber/styrene-butadiene rubber blends. Express Polym Lett 8(9):659-668

Datta J, Głowińska E (2011) Influence of cellulose on mechanical and thermomechanical properties of elastomers obtained from mixtures containing natural rubber. Polimery 11(12): $823-827$

Datta J, Głowińska E (2014) Effect of hydroxylated soybean oil and bio-based propanediol on the structure and thermal properties of synthesised bio-polyurethanes. Ind Crop Prod 61:84-91

Datta J, Kopczyńska P (2015) Effect of kenaf fibre modification on morphology and mechanical properties of thermoplastic polyurethane materials. Ind Crop Prod 74:566-576

Ejikeme PM (2008) Investigation of the physicochemical properties of microcrystalline cellulose from agricultural wastes I: orange mesocarp. Cellulose 15:141-147

Fowler PA, Hughes J, Elias RM (2006) Biocomposites: technology, environmental cerdentials and market forces. J Sci Food Agric 86:1781-1789

Głowińska E, Datta J (2014) A mathematical model of rheological behavior of novel bio-based isocyanate-terminated polyurethane prepolymers. Ind Crop Prod 60:123-129

Głowińska E, Datta J (2015) Structure, morphology and mechanical behaviour of novel bio-based polyurethane composites with microcrystalline cellulose. Cellulose 22:2471-2481

Głowińska E, Kamerke J, Włoch M (2015) Mechanical properties and morphology of biopolyurethane composites reinforced with modified sisal fibers. Przem Chem 94(5):688-693

Hatakeyama H, Kato NNT, Hatakeyama T (2012) Water absorbent polyurethane composites derived from molasses and lignin filled with microcrystalline cellulose. J Mater Sci 47:7254-7261

Kiziltas A, Gardner DJ, Han Y, Yang HS (2011) Thermal properties of microcrystalline cellulose-filled PET-PTT blend polymer composites. J Therm Anal Calorim 103:163-170

Koleśnik-Nykiel P (2013) Influence of microcrystalline cellulose on morphology, structure and selected macroscopic properties of polyurethane elastomers. Master Thesis, Gdańsk University of Technology

Kunaver M, Jasiukaityte E, Čuk N, Oprešnik MSS, Katrašnik T (2011) Biomass waste - a source of raw materials and new energy source. Word Renewable Energy Congress, Linkoping

Li Y, Arthur AJ, Ragauskas J (2012) Kraft lignin-based rigid polyurethane foam. J Wood Chem Technol 32:210-224

Luo X, Mohanty A, Misra M (2013) Lignin as a reactive reinforcing filler for water-blown rigid biofoam composites from soy oil-based polyurethane. Ind Crop Prod 47:13-19

Magnus B, Marie LB, Kristiina O (2007) Extrusion and mechanical properties of highly filled cellulose fibrepolypropylene composites. Compos Part A 38:1922-1931

Mówczyński K (2012) Kompozyty polimerowe: Branża z przyszłością. Chemia i biznes. http://chemiaibiznes.com. 
pl/artykuly/pokaz/143-Kompozyty_polimerowe_Branza_ z_przyszloscia.html

Naheed S, Paridah MT, Mohammad J (2014) A review on potentiality of nano filler/natural fiber filled polymer hybrid composites. Polymers 6:2247-2273

Nanclares J, Petrović ZS, Javni I, Ionescu M, Jaramillo F (2015) Segmented polyurethane elastomers by nonisocyanate route. J Appl Polym Sci. doi:10.1002/app.42492

Oyeniyi Y, Itiola O (2012) The physicochemical characteristic of microcrystalline cellulose, derived from sawdust, agricultural waste products. Int J Pharm Pharm Sci 4(1): 197-200

Prociak A, Rokicki G, Ryszkowska J (2014) Materiały poliuretanowe. Polish Scientific Publishers, Warszawa
Rajczyk M, Stachecki B (2011) Współczesne materiały kompozytowe wybrane kierunki rozwoju nowych technologii. In: Rajczyk J (ed) Budownictwo o zoptymalizowanym potencjale energetycznym. Czestochowa University of Technology, Częstochowa, pp 202-211

Siró I, Plackett D (2010) Microfibrillated cellulose and new nanocomposite materials: a review. Cellulose 17(3):459-494

Tien YI, Wei KH (2001) Hydrogen bonding and mechanical properties in segmented montmorillonite/polyurethane nanocomposites of different hard segment ratios. Polymer 42:3213-3221

Xue BL, Wen JL, Sun RC (2014) Lignin-based rigid polyurethane foam reinforced with pulp fiber: synthesis and characterization. ACS Sustain Chem Eng 2:1474-1480 